\title{
Study on the Influence of Wind Power and Photovoltaic Access to Battery Energy Storage System on Optimized Configuration Benefits
}

\author{
Yicong Liu ${ }^{\text {a }}$, Zongqi Liu \\ School of Electric and Electronic Engineering, North China Electric Power University, Beijing 102206, \\ China \\ aycncepu@163.com
}

Keywords: Battery energy storage system, Distribution Company, Economic benefit, Wind power, Photovoltaic.

\begin{abstract}
This paper presents a hierarchical planning method for battery energy storage system (BESS) operator and the distribution company (DISCO) collaborative planning in the distribution network with application scenarios that BESS operator invests the constructions of BESS. The charge and discharge contract price is chosen as the optimization variable, in order to achieve the optimizing scheduling of BESS. This paper uses the improved particle swarm optimizer method and introduces CauchyGaussian reduction mutation factor to adjust the local optimal extremum. An improved IEEE-33 nodes system is taken as an example. Cases analysis shows that the method allows both DISCO and BESS operators to be profitable. The simulation results show that when equal capacity DG access to the model, the access of wind power is more effective than the access of photovoltaic, whose benefit is more prominent.
\end{abstract}

\section{Introduction}

Battery energy storage system (BESS) has been widely used in developed countries and regions such as Japan, Europe and North America [1], which has the advantages of long service life, high efficiency, and low requirement of geographical conditions. It can be seen that the distribution company (DISCO) and the BESS operator cooperatively regulating the BESS configuration, guiding the energy storage strategy in the form of contract price, can fully exploit the potential benefits of optimizing operation. Different types of distributed generation (DG) have different output characteristics. As the main types of DG, wind power and photovoltaic access to the system have great impact on BESS capacity configuration and charge and discharge contract price fixing. There have been studies on the optimization of BESS in distribution network. In [2], sodium-sulfur battery is taken as an example to model BESS. The simulation results show that reasonable capacity of BESS access to proper location in the distribution network, line loss rate can be reduced. BESS value evaluation model is established in [3], optimizing the overall economic value is taken as the optimization objective. The economic benefit model of BESS investment is established in [4], including energy storage arbitrage revenue, government electricity price subsidy revenue, etc.

This paper proposes a double-layer synergistic control model between the BESS operator and the distribution company. The charge and discharge contract price is chosen as the optimization variable. Considering the wind power and photovoltaic output characteristics, this paper analyzes the different optimization results of equivalent capacity of wind power and photovoltaic access.

\section{Hierarchical Optimization Planning Model}

The coordinated double-layer planning model of the BESS operator and the DISCO is proposed. The upper-layer model is set as simulating the economic dispatching process of the distribution network. The lower-layer model focuses on the optimization of BESS configuration issues, making BESS operators the largest net income, optimizing BESS operation strategy according to the upper contract price and returning the optimized charge and discharge plan to the upper at the same time. 
According to the lower-layer feedback of BESS charge and discharge power, the upper DISCO re-adjust the scheduling process and modify contract price. This loop iterates until the maximum number of iterations is reached or the upper and lower decision variables are less than allowed value.

\subsection{Upper Layer Optimization Model.}

The optimization objective is the maximum difference of DISCO economic benefits before and after the BESS configuration.

$$
\max F_{\mathrm{D}}=B_{\mathrm{dir}}+B_{\mathrm{del}}+B_{\mathrm{env}}+B_{\text {rel }} .
$$

Where, $F_{\mathrm{D}}$ is the increment of DISCO economic benefits before and after the BESS configuration; $B_{\text {dir }}$ is the direct income increment which needs to consider the cost that DISCO purchase electricity from BESS operators and energy storage system charge benefits; $B_{\text {del }}$ is the benefits of delaying the upgrading of power grid; $B_{\text {env }}$ is environmental benefits; $B_{\text {rel }}$ is the benefit of reducing outage cost.

BESS obeys the DISCO scheduling in the fault process. The payment price for participation in the emergency demand side is $\$ 10 / \mathrm{kWh}$ [5]. The remaining parameters and meanings are described in [6].

The upper layer model should satisfy the following constraints:

Contract price range constraint:

$$
0 \leq \lambda_{t} \leq \lambda_{\text {max }}
$$

$\lambda_{t}$ is BESS charging and discharging contract price at time $t ; \lambda_{\max }$ is upper limit of contract price.

System power balance constraint

$$
\sum_{n \in N_{\mathrm{DG}}} p_{\mathrm{DG} . n . t}+p_{\mathrm{g} . t}+p_{B E S . t}^{d}=p_{\mathrm{s} . t}+p_{\mathrm{s} . t}+p_{B E S . t}^{c} .
$$

Where, $p_{\mathrm{g} . t}$ represents the electricity purchasing from upper power grid during time $t ; p_{\mathrm{BES} . t}^{\mathrm{d}}$ and $p_{\mathrm{BES} . t}^{\mathrm{c}}$ are respectively the discharge and charge power of energy storage battery at time $t ; p_{\mathrm{s} . t}$ is total loads of the system at time $t ; p_{\text {ls. } t}$ is system power loss.

Node voltage and line current constraint

$$
\left\{\begin{array}{l}
V_{\min } \leq V_{i} \leq V_{\max } \\
0 \leq I_{i j} \leq I_{i j \cdot \max }
\end{array}\right.
$$

Where, $V_{i}$ is the voltage at node $i ; V_{\min }$ is lower voltage limit; $V_{\max }$ is voltage HI limit; $I_{i j}$ is the current on the line between node $i$ and node $j ; I_{i j \text { max }}$ is line maximum allowable carrying capacity.

\subsection{Lower Layer Optimization Model.}

The lower layer optimization model determines the optimal capacity and optimal power configuration of BESS and the charge and discharge power at all times on the basis of the upper layer given charge and discharge contract price. The objective function is as follows:

$$
\max F_{\mathrm{BESS}}=B_{\text {nop }}+B_{\text {aop }}-C_{\text {tol }} \text {. }
$$

Where, $F_{\text {BESS }}$ is BESS operator's economic benefits; $B_{\text {nop }}$ is BESS in the normal operation through the peak load-shifting to get the operating revenue. $B_{\text {aop }}$ is BESS participating in the emergency demand side response in the process of system failure to obtain failure benefit. $C_{\text {tol }}$ is the BESS configuration costs [7].

The lower layer model should satisfy the following constraints:

Battery can only exist in one of the charging and discharging state in any period of time.

$$
p_{\text {BES.t }}^{\mathrm{d}} \cdot p_{\mathrm{BES} . t}^{\mathrm{c}}=0 \text {. }
$$

The battery state of charge (SOC) is related to the charge/discharge power per time and satisfies the recursive relationship of Eq. 7. In order to ensure maximum flexibility of energy storage system in the next dispatch cycle, the SOC of battery at the initial time is set at 50\% [8].

$$
\begin{gathered}
S_{o c . t}=S_{o c . t-1}+\eta_{c} \Delta T p_{B E S . t}^{c}-\frac{1}{\eta_{d}} \Delta T p_{B E S . t}^{d} \\
S_{o c .0}=50 \%
\end{gathered}
$$

Where $S_{\text {oc. } t}$ is SOC of the energy storage at time $t ; \eta_{\mathrm{c}}, \eta_{\mathrm{d}}$ is BESS charge and discharge efficiency; $\Delta T$ is unit time interval, this paper set $1 \mathrm{~h}$. 


\section{Model Solving Method}

The upper layer model uses the improved particle swarm optimizer (IPSO) to solve [9]. In view of the shortcomings of PSO algorithm which is easy to fall into the local optimum, this paper introduces Cauchy-Gaussian reduction mutation factor [10] to adjust the local optimal extremum. The individual particle position after the Cauchy-Gaussian reduction mutation is shown below.

$$
\begin{gathered}
x_{i}=\left[x_{i, 1} \times \Delta, x_{i, 2} \times \Delta, \ldots, x_{i, \mathrm{~d}} \times \Delta\right] . \\
\Delta=1+\xi((\alpha \times k) / K) \times \delta .
\end{gathered}
$$

Where $\xi$ is variance energy efficiency coefficient; $\delta$ is reduction mutation factor; $K$ is maximum number of iterations. Alternately choose Cauchy mutation and Gaussian mutation according to the iterative process, which can simultaneously improve the accuracy and speed of solution.

The lower layer model is BESS optimal configuration problem, which belongs to the non-convex non-linear optimization problem. It can be solved by YALMIP toolbox in MATLAB [11].

\section{Case Study}

\subsection{System Parameters.}

In this paper, an improved IEEE-33 nodes system is studied, equal capacity of distributed wind power and photovoltaic is introduced respectively, whose location and capacity as shown in Figure 1. The planning basis year peak load is $3.775+\mathrm{j} 2.300 \mathrm{MVA}$. BESS takes the sodium sulfur battery as an example, the battery-related parameters, the upper level grid pollutants discharge condition and real-time electricity prices are shown in literature [7]. The electricity price of this level grid takes the 1.2 times purchase price. The evaluation rate of energy not supplied is $1355 \mathrm{yuan} /(\mathrm{kW} \cdot \mathrm{h})$ [12]. System parameters is shown in Table 1 and Table 2.

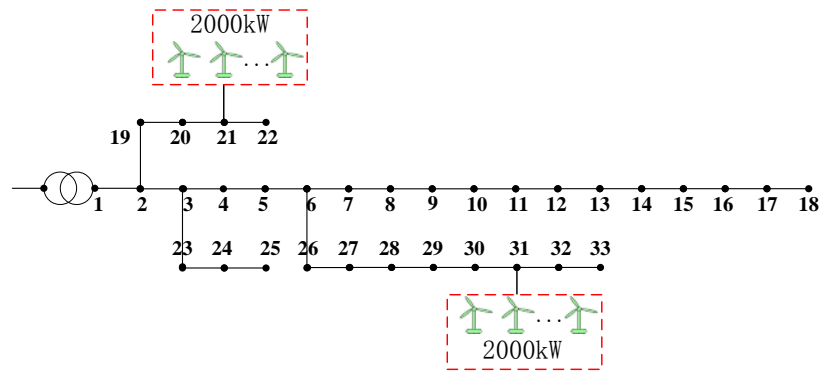

Fig. 1 Improved IEEE-33 nodes system

Table 1. System component parameters

\begin{tabular}{ccc}
\hline Component & Failure rate & Repair rate \\
\hline power line & 0.15 time $/ 102 \mathrm{~km}$ year & $5 \mathrm{~h}$ \\
transformer & 0.35 time $/ 102 \mathrm{~km}$ year & $4 \mathrm{~h}$ \\
circuit breaker & 0.23 time $/ 102 \mathrm{~km}$ year & $3 \mathrm{~h}$ \\
\hline
\end{tabular}

Table 2. Remaining system parameters

\begin{tabular}{|c|c|}
\hline Parameter & Value \\
\hline power line feed-in tariff & $0.42 \mathrm{yuan} /(\mathrm{kW} \cdot \mathrm{h})$ \\
\hline grid upgrade investment & 1 million yuan \\
\hline rate of inflation & $1.5 \%$ \\
\hline
\end{tabular}

\subsection{Results.}

Wind power and photovoltaic have different output characteristics as shown in Fig.2, which have great impact on BESS capacity allocation and charge and discharge contract price fixing. 


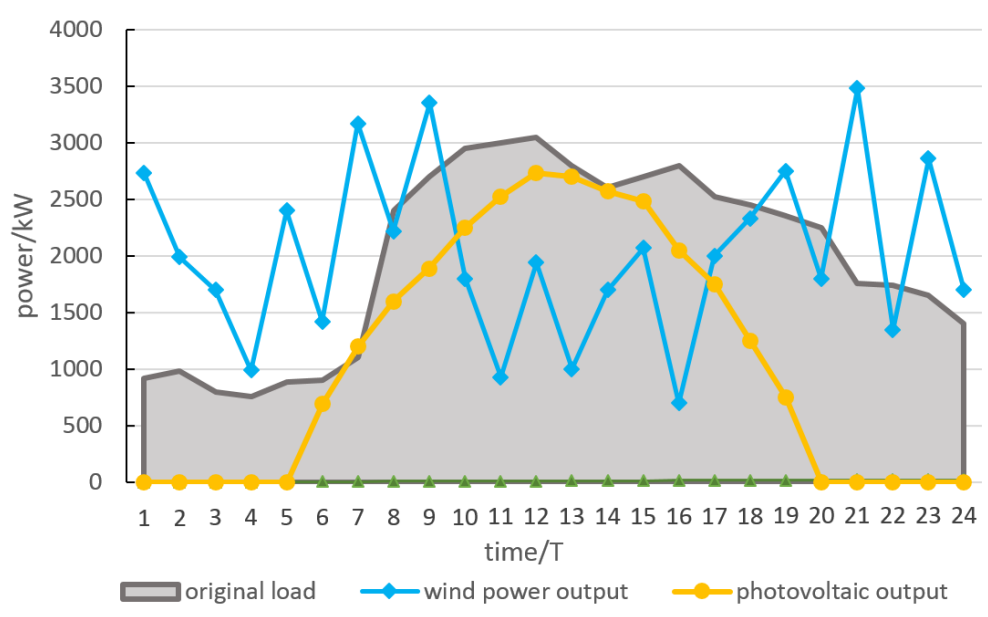

Fig. 2 Wind, photovoltaic output and original load curve

In order to analyze the effect of different DG types on the optimization results of the model. This paper compares the optimization results of two cases. Case 1 is wind power access to system only. Case 2 is photovoltaic of equivalent capacity as the wind power in Case 1 access to system only.

Results are as follows:

Table 3. Optimization results comparison

\begin{tabular}{|c|c|c|}
\hline Item & Case 1 & Case 2 \\
\hline BESS rated capacity $(\mathrm{kW} \cdot \mathrm{h})$ & 3474 & 2907 \\
\hline BESS rated capacity power(kW) & 1158 & 984 \\
\hline Operating revenue(million yuan) & 168.8 & 102.75 \\
\hline Failure revenue(million yuan) & 1.37 & 0.841 \\
\hline Configuration cost(million yuan) & 65.1 & 48.71 \\
\hline BESS net income per year(million yuan) & 105.7 & 54.88 \\
\hline Direct income increment & 75.934 & 73.69 \\
\hline Delaying grid upgrading benefit & 28.545 & 5.774 \\
\hline Environmental benefit & 39.619 & -8.588 \\
\hline Reducing outage loss benefit & 1.885 & 1.466 \\
\hline DISCO total value added benefit & 145.983 & 72.342 \\
\hline
\end{tabular}

It can be seen in Figure 2, the photovoltaic has a normal load regulative characteristics, the original load is greater than the photovoltaic output at all times. Therefore, in Case 2, BESS allocation cannot reduce the electricity that DISCO purchased from the higher level. On the contrary, it will increase electricity DISCO purchase from the higher level, resulting in deterioration of environmental benefits. The environmental benefit of Case 2 is negative in Table 3 can prove this conclusion.

It can also be seen from Table 3 that the rated capacity, rated capacity power and net income of BESS in Case 2 are lower than those in Case 1. It can be expected that if the reduction in environmental benefits is greater than the sum of the other three benefits, it will not be able to find the contract price that BESS and DISCO both be profitable. It can be seen that the types of DG access will affect the DISCO and BESS benefits calculated by this method. When equal capacity DG access to the model, the access of wind power is more effective than the access of photovoltaic, whose benefit is more prominent.

\section{Summary}

This paper presents a double-layer synergistic planning method for BESS optimal configuration in coordination with contract price in the distribution network. The upper layer from the point of view of the DISCO operator to explore the potential benefits of the BESS configuration and set reasonable 
BESS charge and discharge price; the lower layer from the BESS operator point of view, on the basis of the upper layer given contract price, to achieve their own economic interests. Cases shows that the types of DG will affect the DISCO and BESS benefits calculated by this method. The access of wind power is more effective than the access of equivalent capacity photovoltaic, whose benefit is more prominent.

\section{References}

[1]. J.Q. WEN, B. ZENG, J.H. ZHANG. Bi-level Programming Method for Distribution Generator Considering Stakeholders Game Relationship in an Electricity Market Environment [J]. Automation of Electric Power Systems. Vol. 39 (2015) No. 15, p. 61-67.

[2]. Y. Yao, D. Liu, H.Q Liao, et al. Analysis on loss reduction of distribution network with energy storage battery [J]. East China Electric Power. Vol. 38 (2010) No. 5, p. 677-680.

[3]. Z.M. YAN, C.M. WANG, J. ZHENG, et al. Value assessment model of battery energy storage system in distribution network [J]. Electric Power Automation Equipment. Vol. 33 (2013) No. 2, p. 57-61.

[4]. Y.P. XIANG, Z.N. WEI, G.Q SUN, et al. Life Cycle Cost Based Optimal Configuration of Battery Energy Storage System in Distribution Network [J]. Power System Technology. Vol. 39 (2015) No. 1, p. 264-270.

[5]. Nguyen H. T., Cuong T. D., Shaolei R., et al. Incentive Mechanisms for Economic and Emergency Demand Responses of Colocation Datacenters [J]. IEEE Journal on Selected Areas in Communications. Vol. 33 (2015) No. 12, p. 2892-2905.

[6]. LIU W., NIU S., XU H. Optimal planning of battery energy storage considering reliability benefit and operation strategy in active distribution system[J], Journal of Modern Power System Clean Energy. Vol. 5 (2017) No. 2, p. 177-186.

[7]. W.X. LIU, S.Y. NIU, D.G. SHI, et al. Optimal Allocation of ADS Battery Energy Storage Considering Operation Strategy and Investment Subject Benefit [J]. Power System Technology. Vol. 39 (2015) No. 10, p. 2697-2704.

[8]. C. JIANG, W.X. LIU, J.H. ZHANG. Risk Assessment for Power System with Wind Farm and Battery Energy Storage [J]. Power System Technology. Vol. 38 (2014) No. 8, p. 2087-2094.

[9]. X.G. WU, Z.Q. LIU, L.T. TIAN, et al. Energy Storage Device Locating and Sizing for Distribution Network Based on Improved Multi-Objective Particle Swarm Optimizer [J]. Power System Technology. Vol. 38 (2014) No. 12, p. 3405-3411.

[10]. X.X. DU, J.F. ZHANG, Y. GUO, M. JIN. A fruit fly optimization algorithm with Cauchy-Gaussian dynamic reduction mutation [J]. Computer Engineering \& Science. Vol. 38 (2016) No. 6, p. 1171-1176.

[11]. Lofberg J. YALMIP: A toolbox for modeling and optimization in MATLAB. In Proceedings of the 2004 IEEE International Symposium on Computer Aided Control. Systems Design, Taipei, Taiwan, 2-4 Sept. 2004, p. 284-289.

[12]. S.X. ZHANG, H.Z. SHAO, Overall Efficiency Assessment of Power Distribution Network Based on Distribution Network [J]. Journal of Shanghai University of Electric Power, Vol. 31 (2015) No. 1, p. 19-23. 